\title{
Role of Biomarkers in Juvenile Idiopathic Arthritis
}

\author{
Jong Gyun Ahn, M.D., Ph.D. \\ Department of Pediatrics, Severance Children's Hospital, Yonsei University College of Medicine, Seoul, Korea
}

\begin{abstract}
The aim of this review was to identify the utility of biomarkers used in the diagnosis and the monitoring and treatment of Juvenile idiopathic arthritis (JIA). JIA is a heterogeneous group of diseases characterized by arthritis of unknown etiology that lasts for at least 6 weeks, with onset before the age of 16 years. Unlike adult rheumatoid arthritis, JIA is a heterogeneous arthritis with different subtypes. The diagnosis of JIA is based on clinical evaluation and often involves ruling out other causes of arthritis. Many biomarkers have been studied or are under development to define the classifications of JIA, assess disease activity, predict disease course, treatment response, or the risk of relapse. The diagnostic and prognostic use of biomarkers in JIA could be applied differently depending on diverse subtypes or individuals. To obtain the best clinical outcomes in JIA, it is important to understand the pathophysiology of each JIA subtype and to select and use appropriate biomarkers. (J Rheum Dis 2020;27:233-240)
\end{abstract}

Key Words. Juvenile idiopathic arthritis, Biomarkers, Outcome measures

\section{INTRODUCTION}

Juvenile idiopathic arthritis (JIA) is the most common chronic rheumatic disease in childhood, and may result in significant morbidity [1]. JIA refers to the onset of arthritis with no defined cause before 16 years of age and includes symptoms that persist for at least 6 weeks [2]. The diagnosis of JIA can be difficult because JIA is a heterogeneous group of conditions that manifests inflammatory arthritis without a definite test to confirm the diagnosis. Furthermore, there are many diseases that can mimic JIA [3]. The current classification categories created for JIA are primarily for research purposes and are not intended for use as diagnostic criteria in the clinical setting [4]. Therefore, JIA is diagnosed clinically and is based on a combination of presenting signs and symptoms, blood tests, and if necessary, medical imaging. A number of biomarkers have been used or are under development to assist with the diagnosis of JIA. These biomarkers not only help to predict the course of the disease but are also useful to predict the patient's response to treatment and relapse.

This review therefore sought to identify the utility of biomarkers used in the diagnosis and treatment monitoring of JIA.

\section{MAIN SUBJECTS}

The utility of biomarkers used in JIA include classifying the JIA subtypes, evaluating disease activity, predicting the disease course, treatment response, or the risk of relapse. Table 1 summarizes the biomarkers (existing and promising) that can be used in JIA.

\section{Consideration for new classification of JIA}

Several classification systems for chronic arthritis in childhood have been proposed over the past few decades [5]. The older terms "juvenile rheumatoid arthritis," commonly used by the American College of Rheumatology (ACR), and "juvenile chronic arthritis" by the European League Against Rheumatism, were replaced by the term "juvenile idiopathic arthritis" (JIA) at the Pediatric

Received : May 15, 2020, Revised : June 19, 2020, Accepted : July 7, 2020

Corresponding to : Jong Gyun Ahn (iD http://orcid.org/0000-0001-5748-0015

Department of Pediatrics, Severance Children's Hospital, Yonsei University College of Medicine, 50-1 Yonsei-ro, Seodaemun-gu, Seoul 03722, Korea. E-mail : JGAHN@yuhs.ac

Copyright (C) 2020 by The Korean College of Rheumatology.

This is an Open Access article, which permits unrestricted non-commerical use, distribution, and reproduction in any medium, provided the original work is properly cited. 
Table 1. Biomarkers that can be used in juvenile idiopathic arthritis

\begin{tabular}{ll}
\hline \hline \multicolumn{1}{c}{ Utility } & \multicolumn{1}{c}{ Biomarkers } \\
\hline $\begin{array}{l}\text { Biomarkers that define JIA } \\
\text { subtypes }\end{array}$ & RF \\
& HLA-B27 \\
& Anti-CCP \\
& Biomarkers increased \\
& in systemic JIA (S100 \\
& proteins, IL-18) \\
Biomarkers that measure & CRP \\
disease activity & ESR \\
& S100 proteins \\
Biomarkers that predict & MMP-3 \\
disease course & RF \\
& Anti-CCP \\
& Biomarkers predicting MAS \\
& in systemic JIA (ferritin, \\
& platelet count, AST, \\
triglycerides, fibrinogen, \\
soluble CD25, soluble \\
CD163 etc.) \\
response to therapy and relapse & IL-18 \\
\hline
\end{tabular}

JIA: juvenile idiopathic arthritis, RF: rheumatoid factor, HLA: human leukocyte antigen, ANA: antinuclear antibody, CCP: cyclic citrullinatedpeptide, IL: interleukin, CRP: C-reactive protein, ESR: erythrocyte sedimentation rate, MMP-3: matrix metalloproteinase-3, AST; aspartate aminotransferase, MAS: macrophage activation syndrome.

Standing Committee of the International League of Associations for Rheumatology (ILAR) in 1993 [6,7]. In the current classification system established by ILAR, JIA is further categorized into 7 distinct subtypes, based on their presentation within the first 6 months (Table 2). Most pediatric rheumatologists agree that the ILAR criteria are require revision for several reasons: the criteria have been established for more than 20 years, and the number of affected joints or the presence of psoriasis does not reflect a homogeneous immune pathogenesis $[8,9]$. Although there is controversy regarding the method employed to change the criteria, a consensus conference led by the Pediatric Rheumatology International Trials Organization (PRINTO) recently proposed a new classification system that is in the process of validation (Table 3) $[10]$.

\section{Biomarkers used to define the JIA subtypes}

Biomarkers that are useful to classify the subtypes of JIA include rheumatoid factor (RF), human leukocyte antigen (HLA)-B27, antinuclear antibody (ANA), and anti-cyclic citrullinated peptide (CCP) antibodies.

RFs are antibodies directed against the Fc fragment of immunoglobulin $\mathrm{G}(\mathrm{IgG})$. They are heterogeneous and usually composed of IgM; therefore, most assays detect only IgM [11]. RFs cannot be used to diagnose JIA because IgM RFs are rarely found in children younger than 7 years of age, and can be detected not only in children with other autoimmune diseases but also in healthy children. Nevertheless, RFs are an important component of both the ILAR classification criteria and the newly proposed PRINTO criteria (Tables 2 and 3). RFs are most commonly detected in children with a later age at JIA onset and in those with polyarticular involvement [12]. In the PRINTO classification, RF-positive JIA is considered to be the pediatric counterpart of RF-positive rheumatoid arthritis (RA) in adults [10].

HLA-B27 is a class I surface antigen encoded by the B locus in the major histocompatibility complex, and has an affinity for antigenic peptides and presents them to cytotoxic T-lymphocytes [13]. The presence of HLA-B27 is an important part of the inclusion criteria used in the definition of enthesitis-related arthritis (ERA) based on the ILRA criteria or according to the definition of the enthesitis/spondylitis-related JIA provided by PRINTO (Tables 2 and 3). Approximately $60 \% \sim 80 \%$ of children with ERA represent positive for HLA-B27 [12]. Although HLA-B27 is frequently present in these children, the presence or absence of HAL-B27 cannot be relied upon to confirm or exclude the diagnosis of JIA. The allele is an indicator of risk rather than a diagnostic test. HLA-B27 also has a strong association with ankylosing spondylitis (AS), which is notable considering that ERA is thought to be the pediatric counterpart of adult AS.

ANAs are antibodies that can be directed against cellular antigens and are detected predominantly in the nucleus and in other cellular components. ANAs may be found in $5 \% \sim 18 \%$ of healthy children who do not show evidence of arthritis [14], which limits their use for diagnostic testing. However, ANAs are most frequently found in $65 \% \sim 85 \%$ of young girls with oligoarthritis and uveitis $[15,16]$. These findings suggest that ANA positivity may represent a unique condition in JIA. Therefore, the PRINTO proposed a new diagnostic criterion called early-onset ANA-positive JIA that was not addressed in the ILAR criteria (Table 3) [10]. This subtype exists only in JIA and does not have a matching form in adults. 
Table 2. International League of Associations for Rheumatology (ILAR) classification for juvenile idiopathic arthritis

\begin{tabular}{|c|c|}
\hline Categories & Criteria \\
\hline 1. Systemic arthritis & $\begin{array}{l}\text { - Fever of at least } 2 \text { weeks' duration and arthritis in } \geq 1 \text { joint } \\
\text { - Plus one or more of the following: } \\
\text { Erythematous rash } \\
\text { Lymphadenopathy } \\
\text { Serositis } \\
\text { Hepatomegaly and/or splenomegaly } \\
\text { - Exclusions: a, b, c, d }\end{array}$ \\
\hline 2. Oligoarthritis & $\begin{array}{l}\text { - Arthritis affecting } \leq 4 \text { joints during the first } 6 \text { months of disease } \\
\text { There are } 2 \text { subcategories: } \\
\text { Persistent: affect } 4 \text { or fewer joints throughout the disease course } \\
\text { Extended: affect more than } 4 \text { joints after the first } 6 \text { months of disease } \\
\text { - Exclusions: a, b, c, d, e }\end{array}$ \\
\hline 3. Polyarthritis RF-negative & $\begin{array}{l}\text { - Arthritis affecting } \geq 5 \text { joints during the first } 6 \text { months of disease } \\
\text { - Test for RF is negative } \\
\text { - Exclusions: } a, b, c, d, e\end{array}$ \\
\hline 4. Polyarthritis RF-positive & $\begin{array}{l}\text { - Arthritis affecting } \geq 5 \text { joints during the first } 6 \text { months of disease } \\
\text { - Two or more test for RF at least } 3 \text { month apart during the first } 6 \text { months of disease are positive } \\
\text { - Exclusions: } a, b, c, e\end{array}$ \\
\hline 5. Psoriatic arthritis & $\begin{array}{l}\text { - Arthritis and psoriasis, or arthritis and at least } 2 \text { of the following: } \\
\text { Dactylitis } \\
\text { Nail pitting or onycholysis } \\
\text { Psoriasis in a first-degree relative } \\
\text { - Exclusions: b, c, d, e }\end{array}$ \\
\hline 6. Enthesitis-related arthritis & $\begin{array}{l}\text { - Arthritis and enthesitis, or arthritis or enthesitis with at least } 2 \text { of following: } \\
\text { The presence of or a history of sacroiliac joint tenderness and/or inflammatory } \\
\text { lumbosacral pain } \\
\text { The presence of HLA-B27 antigen } \\
\text { Onset of arthritis in a male over } 6 \text { years of age } \\
\text { Acute (symptomatic) anterior uveitis } \\
\text { History of ankylosing spondylitis, enthesitis related arthritis, sacroiliitis with inflammatory } \\
\text { bowel disease, Reiter's syndrome, or acute anterior uveitis in a first-degree relative } \\
\text { - Exclusions: a, d, e }\end{array}$ \\
\hline 7. Undifferentiated arthritis & - Arthritis that fulfills criteria in no category or in 2 or more of the above categories \\
\hline
\end{tabular}

RF: rheumatoid factor, HLA: human leukocyte antigen. One of the major aims of the ILAR classification is the mutual exclusivity of the subtypes. Therefore, the following list of possible exclusion for each category was defined; a) Psoriasis or a history ofpsoriasis in the patient or first-degree relative; b) Arthritis in an HLA-B27-positive male beginning after the sixth birthday; c) Ankylosing spondylitis, enthesitis-related arthritis, sacroiliitis with inflammatory bowel disease or acute anterior uveitis, or a history of one of these disorders in a first-degree relative; $d$ ) The presence of immunoglobulin $\mathrm{M}$ rheumatoid factor and at least two occasions at least 3 months a part; e) The presence of systemic juvenile idiopathic arthritis in the patient.

Anti-CCP antibodies are a group of autoantibodies that are directed against peptides and proteins that are citrullinated. Although the major clinical relevance of anti-CCP antibodies is their association with adult RA, they are also detected in children with JIA. In a study by Tebo et al. [17], anti-CCP antibodies were found in $73 \%$ of children with RF-positive polyarticular JIA, 19\% with extended oligoarticular JIA, $13 \%$ with systemic JIA, $8 \%$ with RF-negative polyarticular JIA, $4 \%$ with ERA or persistent oligoarticular JIA, and in $2 \%$ of controls. Although an-
ti-CCP antibodies have not yet been included in the ILAR classification criteria, they are included in the new PRINTO criteria, in which RF-positive JIA was defined as arthritis that persisted over 6 weeks, along with 2 positive tests for RF at least 3 months apart, or at least 1 positive test for anti-CCP antibodies (Table 3).

Among the JIA subtypes, systemic JIA is considered to be an autoinflammatory condition that is both clinically and immunologically distinct from the other categories of JIA and therefore requires different therapy. In addition, 
Table 3. Pediatric Rheumatology International Trials Organization (PRINTO) classification for juvenile idiopathic arthritis

\begin{tabular}{|c|c|}
\hline Categories & Criteria \\
\hline 1. Systemic JIA & $\begin{array}{l}\text { - Fever of unknown origin that is documented to be daily for at least } 3 \text { consecutive days and } \\
\text { reoccurring over a duration of at least } 2 \text { weeks and } \\
\text { - Accompanied by } 2 \text { major criteria OR } 1 \text { major criterion and } 2 \text { minor criteria. Major criteria } \\
\text { are (1) evanescent erythematous rash; and (2) arthritis. Minor criteria are (1) generalized } \\
\text { lymph node enlargement and/or hepatomegaly and/or splenomegaly; (2) serositis; (3) } \\
\text { arthralgia lasting } 2 \text { weeks or longer (in the absence of arthritis); and (4) leukocytosis ( } \geq \\
15,000 / \mathrm{mm}^{3} \text { ) with neutrophilia }\end{array}$ \\
\hline 2. RF-positive JIA & $\begin{array}{l}\text { - Arthritis for } \geq 6 \text { weeks, and } \\
\text { - Association with } 2 \text { positive tests for RF at least } 3 \text { months apart or at least } 1 \text { positive test for } \\
\text { antibodies to cyclic citrullinated peptide }\end{array}$ \\
\hline 3. Enthesitis/spondylitis-related JIA & $\begin{array}{l}\text { - Peripheral arthritis and enthesitis, or } \\
\text { - Arthritis or enthesitis, plus } \geq 3 \text { months of inflammatory back pain and sacroiliitis on } \\
\text { imaging, or } \\
\text { - Arthritis or enthesitisplus } 2 \text { of the following: (1) sacroiliac joint tenderness; (2) inflammatory } \\
\text { back pain; (3) presence of HLA-B27 antigen; (4) acute (symptomatic) anterior uveitis; and } \\
\text { (5) history of a spondyloarthritis in a first-degree relative }\end{array}$ \\
\hline 4. Early-onset ANA-positive JIA & $\begin{array}{l}\text { - Arthritis for } \geq 6 \text { weeks, and } \\
\text { - Early-onset ( } \leq 6 \text { years), and } \\
\text { - Presence of } 2 \text { positive ANA tests with a titer } \geq 1 / 160 \text { (tested by immunofluorescence) at } \\
\text { least } 3 \text { months apart } \\
\text { Exclusions are systemic JIA, RF-positive arthritis, and enthesitis/spondylitis-related JIA }\end{array}$ \\
\hline 5. Other JIA & $\begin{array}{l}\text { - Arthritis for } \geq 6 \text { weeks } \\
\text { - Does not fit criteria for disorders } 1 \text { to } 4\end{array}$ \\
\hline 6. Unclassified JIA & $\begin{array}{l}\text { - Arthritis for } \geq 6 \text { weeks } \\
\text { - Fits }>1 \text { disorder } 1 \sim 4\end{array}$ \\
\hline
\end{tabular}

JIA: juvenile idiopathic arthritis, RF: rheumatoid factor, ANA: antinuclear antibody, HLA: human leukocyte antigen.

children with this subtype are at risk of a severe, life-threatening complication called macrophage activation syndrome (MAS). In this unique type of JIA, the concentrations of S100 proteins such as S100A8-S100A9, S100A12, and interleukin (IL)-18 are increased in the plasma of children with systemic JIA [18]; therefore, these proteins may be supportive candidate biomarkers for the diagnosis of systemic JIA.

\section{Biomarkers used to measure disease activity}

The biomarkers most commonly used to assess disease activity in JIA are C-reactive protein (CRP) and erythrocyte sedimentation rate (ESR). CRP is an acute phase protein of hepatic origin the expression of which increases following IL- 6 secretion by macrophages and T cells. CRP levels begin to increase within hours of the onset of inflammation, with levels peaking between 1 and 3 days [14]. The plasma half-life of CRP is 19 hours, making it a more sensitive and accurate reflection of the acute phase response than ESR [19]. In addition, CRP levels normalize more rapidly than ESR in response to therapy.
However, CRP does not have sufficient specificity to differentiate infectious from noninfectious inflammation in JIA. ESR is the rate at which red blood cells settle though plasma to form a sediment in whole blood in a standardized tube over a period of 1 hour. ESR is also a non-specific measure of inflammation that is included in both the Juvenile Arthritis Disease Activity Score (JADAS) and the core response variables identified by the ACR, which are the standardized and certified assessment tools of JIA disease activity. The JADAS includes 4 measures: physician global assessment of disease activity, parent/patient global assessment of well-being, active joint count, and ESR [20]. The ACR pediatric core criteria for JIA comprises 6 items: physician global assessment of disease activity, parent/patient global assessment of overall well-being, functional ability, number of joints with active arthritis, number of joints with limited range of motion, and ESR [21].

Other candidate biomarkers that are useful to measure disease activity are the $\mathrm{S} 100$ proteins and matrix metalloproteinase 3 (MMP3). The S100 proteins are a class of 
pro-inflammatory calcium-binding proteins that are involved in the regulation of calcium homeostasis, enzyme activities, energy metabolism, cell growth and differentiation, and cytoskeletal dynamics [22]. In response to injurious or infectious stimuli, they also act as damage-associated molecular pattern molecules, with increased expression and release at sites of inflammation [23]. The most studied S100 proteins in JIA are S100A8 (also known as myeloid-related protein [MRP] 8 and calgranulin A), S100A9 (also known as MRP 14 and calgranulin B), and S100A12 (also known as MRP 6 and calgranulin C). S100A8 and S100A9 often exist as a complex of S100A8 and S100A9, (also known as calprotectin, and S100A8-S100A9), which is the most prevalent form under most physiological conditions. Increased levels of S100A8-S100A9 and S100A12 in the serum and synovial fluid were shown to correlate with disease activity in JIA, suggesting that these proteins may be promising markers for monitoring disease activity [24-26].

MMP-3 is an enzyme that in humans is involved in the breakdown of extracellular matrix, and may induce degradation of cartilage and bone in arthritis [27]. Concentrations of MMP-3 in the serum were higher in children with ERA than in healthy subjects and were correlated with clinical parameters of disease activity $[28,29]$. Therefore, MMP-3 is expected to serve as a useful biomarker for monitoring disease activity in JIA.

\section{Biomarkers used to predict the disease course}

RFs and anti-CCP antibodies are not only components of the classification criteria for JIA, but are also important predictors of disease prognosis. Older children with RF tend to have a longer disease duration, subcutaneous rheumatoid nodules or articular erosions, or a poorer functional class, which mimics adult RA $[12,18]$. In most studies, anti-CCP antibodies have been detected predominantly in patients with RF-positive polyarticular JIA [17]. The prognostic value of anti-CCP antibodies in JIA is yet to be studied, but in small studies they seem to be associated with a worse prognosis [30,31].

MAS is an aggressive and life-threatening complication of systemic inflammatory disorders. MAS occurs most frequently with systemic JIA [32]. The hallmark clinical features of MAS include high fever, hepatosplenomegaly, lymphadenopathy, hemorrhagic manifestations, and encephalopathy [33]. The characteristic laboratory features are pancytopenia, liver dysfunction, disseminated intravascular coagulation, hypofibrinogenemia, hypoalbuminemia, hyperferritinemia, hypertriglyceridemia, increased levels of lactate dehydrogenase, soluble CD25, soluble CD163, and decreased ESR levels [33]. With the recognition that MAS is clinically similar to hemophagocytic lymphohistiocytosis (HLH), some have applied the HLH-2004 diagnostic guidelines to the diagnosis of MAS (Table 4) [34]. However, the main shortcoming of using HLH-2004 guidelines is that some individual criteria may not be met

Table 4. Diagnostic criteria for macrophage activation syndrome

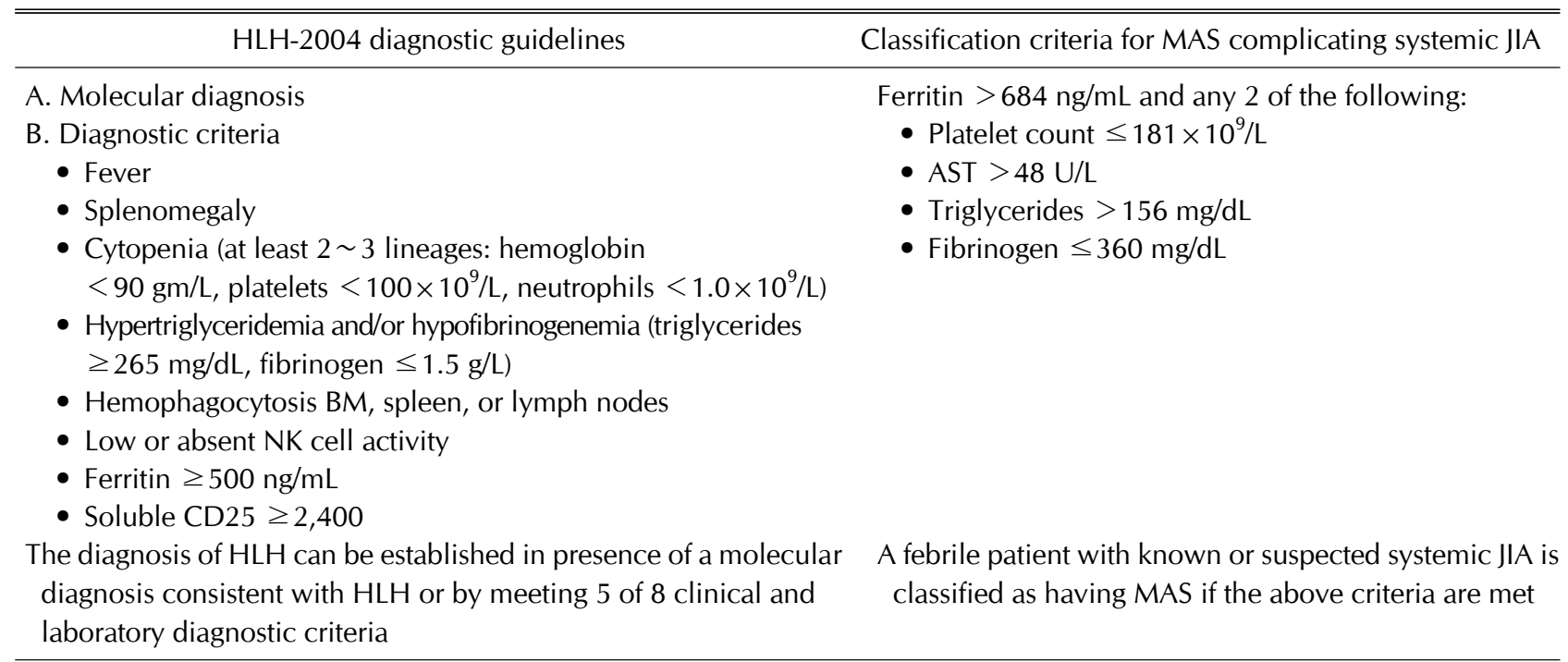

HLH: hemophagocytic lymphohistiocytosis, BM: bone marrow, MAS: macrophage activation syndrome, AST: aspartate aminotransferase, NK: natural killer cells. 
for systemic JIA patients. Due to the remarkable inflammatory properties of systemic JIA, a relative decrease in leukocyte count, platelet count or fibrinogen level may be more useful for early diagnosis of systemic JIA than the absolute reduction required by the HLH-2004 standard. Therefore, the classification criteria of MAS complicating systemic JIA were developed in 2014, based on a combination of expert consensus, evidence from the medical literature, and analysis of patient data (Table 4) [34].

\section{Biomarkers that predict response to therapy and risk for relapse}

The S100 proteins are not only biomarkers for disease activity monitoring in JIA, but also serve as useful biomarkers to predict the response to treatment or disease flares in JIA. High serum levels of S100A8-S100A9 proteins before anti-rheumatic therapies were associated with good responses to methotrexate [35-37], and anti-tumor necrosis factor (TNF) agents [36]. In contrast, the higher levels of S100A8-S100A9 in the serum during remission were associated with a risk of relapse after discontinuation of methotrexate, which supported the hypothesis that the levels of these proteins in the serum could be useful parameters to inform the decision to discontinue treatment [37].

Similar to the findings for S100A8-S100A9, JIA patients with increased levels of serum S100A12 were also more likely to respond favorably to methotrexate or anti-TNF treatment. Increased levels of serum S100A12 during remission were associated with an increased risk of disease flare [38-40]. Similar to non-systemic JIA, increased serum levels of S100A8-S100A9 during clinical remission was also a useful biomarker to predict relapse after therapy withdrawal in systemic JIA [25,35]. IL-18 and S100A8-S100A9 serum levels may be candidate biomarkers for response to therapy in systemic JIA [41]. IL-18 serum levels increased in 4 out of 8 children who experienced failure in tapering of therapy and slightly increased in only 1 out of 7 patients who experienced successful tapering of therapy [42]. S100 proteins and IL-18 are considered for useful markers for predicting treatment response and relapse in systemic JIA and for the diagnosis of the JIA subtype.

\section{CONCLUSION}

Biomarkers serve as useful tools for the diagnosis of JIA subtypes, prediction of disease progression, and estab- lishment of treatment strategies by assessing the response to therapy and relapse risk. The current classification of JIA remains a challenging area, especially given the heterogeneous nature of the disease. Therefore, to achieve the best outcome, it is important to carefully select appropriate biomarkers based on the disease subtype. As the genetic and pathophysiological understanding of JIA improves, new classification systems will define homogeneous groups of children, each with a biologically distinct disease. The identification of new biomarkers with more effective diagnostic/prognostic value could help to achieve the ultimate goal of facilitating the implementation of targeted therapies and tailored treatment interventions and improving remission rates while minimizing disease damage.

\section{CONFLICT OF INTEREST}

No potential conflict of interest relevant to this article was reported.

\section{REFERENCES}

1. Harris JG, Kessler EA, Verbsky JW. Update on the treatment of juvenile idiopathic arthritis. Curr Allergy Asthma Rep 2013;13:337-46.

2. Prakken B, Albani S, Martini A. Juvenile idiopathic arthritis. Lancet 2011;377:2138-49.

3. Kim KH, Kim DS. Juvenile idiopathic arthritis: diagnosis and differential diagnosis. Korean J Pediatr 2010;53:931-5.

4. Aggarwal R, Ringold S, Khanna D, Neogi T, Johnson SR, Miller A, et al. Distinctions between diagnostic and classification criteria? Arthritis Care Res (Hoboken) 2015;67: 891-7.

5. Petty RE, Southwood TR, Manners P, Baum J, Glass DN, Goldenberg J, et al.; International League of Associations for Rheumatology. International League of Associations for Rheumatology classification of juvenile idiopathic arthritis: second revision, Edmonton, 2001. J Rheumatol 2004;31: 390-2.

6. Fink CW. Proposal for the development of classification criteria for idiopathic arthritides of childhood. J Rheumatol 1995;22:1566-9.

7. Petty RE, Southwood TR, Baum J, Bhettay E, Glass DN, Manners P, et al. Revision of the proposed classification criteria for juvenile idiopathic arthritis: Durban, 1997. J Rheumatol 1998;25:1991-4.

8. Martini A. It is time to rethink juvenile idiopathic arthritis classification and nomenclature. Ann Rheum Dis 2012; 71:1437-9.

9. Martini A. Are the number of joints involved or the presence of psoriasis still useful tools to identify homogeneous disease entities in juvenile idiopathic arthritis? J Rheumatol 2003;30:1900-3. 
10. Martini A, Ravelli A, Avcin T, Beresford MW, Burgos-Vargas $\mathrm{R}$, Cuttica R, et al.; Pediatric Rheumatology International Trials Organization (PRINTO). Toward new classification criteria for juvenile idiopathic arthritis: first steps, Pediatric Rheumatology International Trials Organization international consensus. J Rheumatol 2019;46:190-7.

11. Ingegnoli F, Castelli R, Gualtierotti R. Rheumatoid factors: clinical applications. Dis Markers 2013;35:727-34.

12. Petty RE, Laxer RM, Wedderburn LR. Juvenile idiopathic arthritis. In: Petty RE, Laxer RM, Lindsley CB, Wedderburn LR, eds. Textbook of pediatric rheumatology. 7th ed. Philadelphia, Elsevier, 2016, p. 188-204.e6.

13. Bowness P. HLA B27 in health and disease: a double-edged sword? Rheumatology (Oxford) 2002;41:857-68.

14. Akikusa J, Choo S. Laboratory investigations. In: Petty RE, Laxer RM, Lindsley CB, Wedderburn LR, eds. Textbook of pediatric rheumatology. 7th ed. Philadelphia, Elsevier, 2016, p. 117-28.e6.

15. Saurenmann RK, Levin AV, Feldman BM, Laxer RM, Schneider R, Silverman ED. Risk factors for development of uveitis differ between girls and boys with juvenile idiopathic arthritis. Arthritis Rheum 2010;62:1824-8.

16. Angeles-Han ST, Pelajo CF, Vogler LB, Rouster-Stevens K, Kennedy C, Ponder L, et al.; CARRA Registry Investigators. Risk markers of juvenile idiopathic arthritis-associated uveitis in the Childhood Arthritis and Rheumatology Research Alliance (CARRA) Registry. J Rheumatol 2013; 40:2088-96.

17. Tebo AE, Jaskowski T, Davis KW, Whiting A, Clifford B, Zeft A, et al. Profiling anti-cyclic citrullinated peptide antibodies in patients with juvenile idiopathic arthritis. Pediatr Rheumatol Online J 2012;10:29.

18. Swart JF, de Roock S, Prakken BJ. Understanding inflammation in juvenile idiopathic arthritis: how immune biomarkers guide clinical strategies in the systemic onset subtype. Eur J Immunol 2016;46:2068-77.

19. Pepys MB, Hirschfield GM. C-reactive protein: a critical update. J Clin Invest 2003;111:1805-12.

20. Consolaro A, Ruperto N, Bazso A, Pistorio A, Magni-Manzoni $S$, Filocamo G, et al.; Paediatric Rheumatology International Trials Organisation. Development and validation of a composite disease activity score for juvenile idiopathic arthritis. Arthritis Rheum 2009;61:658-66.

21. Cassidy JT, Levinson JE, Bass JC, Baum J, Brewer EJ Jr, Fink $\mathrm{CW}$, et al. A study of classification criteria for a diagnosis of juvenile rheumatoid arthritis. Arthritis Rheum 1986;29: 274-81.

22. Donato R, Cannon BR, Sorci G, Riuzzi F, Hsu K, Weber DJ, et al. Functions of $\mathrm{S} 100$ proteins. Curr Mol Med 2013;13:24-57.

23. Austermann J, Spiekermann C, Roth J. S100 proteins in rheumatic diseases. Nat Rev Rheumatol 2018;14:528-41.

24. Foell D, Roth J. Proinflammatory S100 proteins in arthritis and autoimmune disease. Arthritis Rheum 2004;50: 3762-71.

25. Holzinger D, Frosch M, Kastrup A, Prince FH, Otten MH, Van Suijlekom-Smit LW, et al. The Toll-like receptor 4 agonist MRP8/14 protein complex is a sensitive indicator for disease activity and predicts relapses in systemic-onset juvenile idiopathic arthritis. Ann Rheum Dis 2012;71:974-80.

26. de Jager W, Hoppenreijs EP, Wulffraat NM, Wedderburn
LR, Kuis W, Prakken BJ. Blood and synovial fluid cytokine signatures in patients with juvenile idiopathic arthritis: a cross-sectional study. Ann Rheum Dis 2007;66:589-98.

27. Emonard H, Grimaud JA. Matrix metalloproteinases. A review. Cell Mol Biol 1990;36:131-53.

28. Myles A, Aggarwal A. Expression of Toll-like receptors 2 and 4 is increased in peripheral blood and synovial fluid monocytes of patients with enthesitis-related arthritis subtype of juvenile idiopathic arthritis. Rheumatology (Oxford) 2011;50:481-8.

29. Viswanath V, Myles A, Dayal R, Aggarwal A. Levels of serum matrix metalloproteinase-3 correlate with disease activity in the enthesitis-related arthritis category of juvenile idiopathic arthritis. J Rheumatol 2011;38:2482-7.

30. Syed RH, Gilliam BE, Moore TL. Rheumatoid factors and anticyclic citrullinated peptide antibodies in pediatric rheumatology. Curr Rheumatol Rep 2008;10:156-63.

31. Hamooda M, Fouad H, Galal N, Sewelam N, Megahed D. Anti-cyclic citrullinated peptide antibodies in children with juvenile idiopathic arthritis. Electron Physician 2016;8: 2897-903.

32. Behrens EM, Beukelman T, Paessler M, Cron RQ. Occult macrophage activation syndrome in patients with systemic juvenile idiopathic arthritis. J Rheumatol 2007;34:1133-8.

33. Ravelli A, Grom AA, Behrens EM, Cron RQ. Macrophage activation syndrome as part of systemic juvenile idiopathic arthritis: diagnosis, genetics, pathophysiology and treatment. Genes Immun 2012;13:289-98.

34. Ravelli A, Minoia F, Davì S, Horne A, Bovis F, Pistorio A, et al.; Paediatric Rheumatology International Trials Organisation; Childhood Arthritis and Rheumatology Research Alliance; Pediatric Rheumatology Collaborative Study Group; Histiocyte Society. 2016 Classification criteria for macrophage activation syndrome complicating systemic juvenile idiopathic arthritis: a European league against Rheumatism/ American College of Rheumatology/Paediatric Rheumatology International Trials Organisation collaborative initiative. Arthritis Rheumatol 2016;68:566-76.

35. Moncrieffe H, Ursu S, Holzinger D, Patrick F, Kassoumeri L, Wade A, et al. A subgroup of juvenile idiopathic arthritis patients who respond well to methotrexate are identified by the serum biomarker MRP8/14 protein. Rheumatology (Oxford) 2013;52:1467-76.

36. Anink J, Van Suijlekom-Smit LW, Otten MH, Prince FH, van Rossum MA, Dolman KM, et al. MRP8/14 serum levels as a predictor of response to starting and stopping anti-TNF treatment in juvenile idiopathic arthritis. Arthritis Res Ther 2015;17:200.

37. Foell D, Wulffraat N, Wedderburn LR, Wittkowski H, Frosch M, Gerss J, et al.; Paediatric Rheumatology International Trials Organization (PRINTO). Methotrexate withdrawal at 6 vs 12 months in juvenile idiopathic arthritis in remission: a randomized clinical trial. JAMA 2010; 303:1266-73.

38. Gohar F, Anink J, Moncrieffe H, Van Suijlekom-Smit LWA, Prince FHM, van Rossum MAJ, et al. S100A12 is associated with response to therapy in juvenile idiopathic arthritis. J Rheumatol 2018;45:547-54.

39. Yamasaki Y, Takei S, Imanaka H, Nerome Y, Kubota T, Nonaka $Y$, et al. Prediction of long-term remission of oligo/ polyarticular juvenile idiopathic arthritis with S100A12 and 
vascular endothelial growth factor. Mod Rheumatol 2016; 26:551-6.

40. Gerss J, Roth J, Holzinger D, Ruperto N, Wittkowski H, Frosch M, et al.; Paediatric Rheumatology International Trials Organization (PRINTO). Phagocyte-specific S100 proteins and high-sensitivity $\mathrm{C}$ reactive protein as biomarkers for a risk-adapted treatment to maintain remission in juvenile idiopathic arthritis: a comparative study. Ann Rheum Dis 2012;71:1991-7.

41. Vastert S, Prakken B. Update on research and clinical trans- lation on specific clinical areas: from bench to bedside: how insight in immune pathogenesis can lead to precision medicine of severe juvenile idiopathic arthritis. Best Pract Res Clin Rheumatol 2014;28:229-46.

42. Vastert SJ, de Jager W, Noordman BJ, Holzinger D, Kuis W, Prakken BJ, et al. Effectiveness of first-line treatment with recombinant interleukin-1 receptor antagonist in steroid-naive patients with new-onset systemic juvenile idiopathic arthritis: results of a prospective cohort study. Arthritis Rheumatol 2014;66:1034-43. 